THE GIANTS OF PRE-SOPHISTIC GREEK PHILOSOPHY 


\title{
THE GIANTS OF PRE-SOPHISTIC GREEK PHILOSOPHY
}

\author{
AN ATTEMPT TO RECONSTRUCT THEIR THOUGHTS
}

by

FELIX M. CLEVE

VOLUME ONE

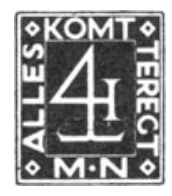

THE HAGUE / MARTINUS NIJHOFF / I 965 
ISBN 978-94-015-2221-2

ISBN 978-94-015-3458-I (eBook)

DOI $10.1007 / 978-94-015-3458-I$

Copyright 1965 by Martinus Nijhoff, The Hague, Netherlands Softcover reprint of the hardcover 1 st edition 1965

All rights reserved, including the right to translate or to reproduce this book or parts thereof in any form 
This work is meant to honor the memory

of

\section{ADOLF STÖHR}

(I855-I92I)

whose philosophy, as Ernst Mach predicted, "will be understood and admired in 200 years."

If there is anything in these pages the reader will like, he may give Stöhr full credit for it.

For whatever the reader will dislike he may blame the author. 


\title{
TABLE OF CONTENTS
}

VOLUME ONE

\author{
Acknowledgments $[\mathrm{XV}]$
}

Foreword [XVII]

Sources and Motives of Philosophy [XXII]

\section{Religious Reformers}

\section{XENOPHANES OF COLOPHON}

Xenophanes and Polytheism 6-The Heis Megistos 8 - The Body of the God ro - The Bodies of the Mortals 15 - The Sun, the Moon, and the Stars 18 - A Motive Organ of the Body of the God 20-The Mind of the God 21 - One and All 23 - What the Doctrine of Xenophanes Properly Is 26 - Xenophanes, the Prophet 27 - Xenophanes - a Sceptic? 28

\section{HERACLITUS OF EPHESUS}

Introduction

The Death of Heraclitus 33 - A Persisting Problem 35 - Heraclitus' Apostasy 36 - No Natural Philosophy 37

The Proton and Its Transformations

Not "Pyr," but "Pyr Aeizoon" 40 - The Term "Logos" 4I - Pyr Aeizoon, Incandescing and Going Out 43 - Intermezzo Grammatico 45-Ekpyrosis 47 - The Transformations 49-And what about the Air? 5I - Prester 53 - The "Metron" 54 - The Circle and the Way Up and Down 55 - Transformation Also in Spirit 56 - The World Is Not Eternal 57 
Immortality

The Meanings of Psyche 58 - The Stream Metaphor 6I - Pre-Existence and Post-Existence of the Psyches 64 - Immortality 66 - The Will to Live and the Will to Die 69-Crux Philologorum 7o-Stöhr's Solution of the Puzzle 73 - Transmigration of Souls? 76

His Eternity the Logos

"Separated from All Things..." 77-No "Pantheism" 78 - Kamatos, Chresmosyne, Koros 79 - Fight, Injustice, Compulsion 80 - Play of a Child 83 - "Playing Child" versus "Omniscient Judge" 87

\section{"Gran Teatro del Mundo"}

Sleep-Walking Actors 88 - A Frontier of Hellenic Thinking 9o - The Law of the One 91 - Some Unavoidable Philology 93 - They Do not Grasp the Meaning of Their Doings ... 94-Playing Hide-and-Seek 96 - The Problem of Free Will 98 - "The Psyches Smell of Death" 98 - Playthings of the Child 99 - The Fight in Everybody's Heart 100 "To the God All Things Are Beautiful" Ior - Hidden Harmony $102-$ The Twofold Beauty of the Universe ro3

Redemption

"Credo, ut Intelligam" ro6 - Knowledge and Faith ro8 - The Multitude Is Not Redeemable I Io... - No Inconsistency I I I - Prophet and Redeemer II 2 - The Heraclitean Creed II3 - Heraclitus versus Zarathustra II 4 - Heraclitus and Xenophanes II6 - Heraclitus and Goethe II 7

Heraclitus and Posterity

The First Two Hundred Years II 8 - The Platonic Heraclitus II9Revival in Stoicism I20 - Outside and After Stoicism I22 - The Modern Heraclitus Renaissance I 23 - History of a Basic Heraclitean Idea I 24 - A Platonic Echo I25 - From Bion to Epictetus I26 - The Next Thousand Years I27 - From Teatro del Mundo to Welttheater 128

\section{Philosophers of Nature}

Water Air Ether I36 - The Meaning of Psyche with the Transformists I37 - The Indian Analogy I38 - Anaximenes' View of Psyche I 40 - The View of Diogenes I4I - No Generatio Spontanea in the Modern Sense I43 - The Label Problem I43 


\section{Anaximander of Miletus}

The Scientist

Interest in Biological Problems I45 - Anaximander, a Forerunner of Darwin? I46 - A Misunderstanding by Plutarch 147 - The First Greek Writing in Prose 149

\section{The Philosopher}

Is Anaximander a Transformist? I 49 - Is It Alloiosis or Ekkrisis? I 50 - Attempt at a Decisive Answer I53 - A Welcome Confirmation I55Divinity of the Apeiron ${ }_{5} 6$ - The Meaning of Struggle and Destruction 158 - That Controversial Sentence... 160 - The Most Serious Problem I6I - Those Innumerable So-Called Worlds I63

\section{THE AGENETISTS}

I. Anaxagoras of Klazomenai

Introduction

Three Different Biographies I69 - Topic for an Historical Novel... I7I - Time Is not Reversible... I7I

\section{THE CONSTITUENTS OF THE U NIVERSE}

The Elements and Their Moiras

Aristotelian Reports I73 - An Old Question and a New Answer I75Essence of the Anaxagorean Elements 177 - The Ostensibly Infinite Number of the Elements 178 - The Distinctive Feature 179 - The Primary Relation and Its Dual Working 180 - Equally Infinite Particles of Each Element I8I - "The Great" and "The Small" I8I Infinite Geometrical Divisibility 182 - Infinity of Space Filled I84 A Strange Juxtaposition and an Attempt at Solving the Riddle 184An Aggregation Terminology 187

Nous, the Ruler Element and Construction Engineer

Homogeneity, Relative and Absolute, and Why Snow Is also Black and Warm I90 - Spatial Extensiveness of Nous I92 - Nous' Immiscibility as a Prerequisite to Its Power 192 - Structure of the Anaxagorean Molecule I93 - Molecule: the "Grown-Together" I94 The Anaxagorean and the Modern Molecules I95 - Impenetrability, Motion Resistance, Movability 196 - The Divine Mechanician 197 Without Renunciation or Ideal. . I98

\section{COSMOGONY}

The Primordial Condition

"Pantahomou" 20I - An Endorsement by Aristotle 204 - "Keeping Itself at a Standstill. .." 205 - The Whereabouts of Nous 206 
First Means of Cosmopoeia: Differentiation

Disengagement of the Checked Qualities 208 - The Beginning of Cosmopoeia 210 - Why Cosmogony Had To Start from One Point 213 - Peri-échon, Proskrithénta, Apokekriména 214 - Exegetic Paraphrase of Fragment Number One 215

\section{Second Means of Cosmopoeia: Rotation}

The Two Sorts of Motion and Their Allotment to Two Principles 218 A Mental Experiment 219 - The Effects of Rotation upon the Earth and the Waters and upon the Original Line of Fall 220 - Why the Rotation of the Earth Has Been Passed Over in Silence 221 - An Endorsement by Plutarch 222 - Intrinsic Reasons for the Rotation of the Earth 223 - The Effects of Rotation upon Air and Ether 224 Rotation and Stratification 225 - How the Earth Remains Suspended 225

\section{Differentiation and Rotation Acting Together}

The Proskrithenta and Their Conglomerations 228 - Why Angular Velocity and Centrifugal Force Must Increase from Without Inwards 229 - Origin of the Stars 230 - How Anaxagoras Came to His Hypothesis 232 - The Stone of Aigospotamoi 232 - Will the Stars Crash Down to the Earth in Time to Come? 234 - Apparent and Real Magnitude of the Stars 235 - That Difficult Moon... 236 Anaxagoras' Invisible Celestial Bodies 238

Third Means of Cosmopoeia: Dismemberment of the Axis

Individual Rotation for Every Sphere 239 - Explanation of the Milky Way 240 - The Orbits and the Turnings of the Sun and of the Moon 24I - When Will Cosmogony Come to Its End? 243

"THERE ARE SOME IN WHICH NOUS, TOO, IS CONTAINED"

The Bodies

Construction against Stratification 244 - If Nous Were Like the God of the Bible... 244 - Creatio ex nihilo - Viewed Psychologically 247 "Primordial Generation" and "Generation from One Another" 249 First Measure against Decay: Breathing 249 - The Meaning of "Psyche" 250 - "Larger Psyche" and "Smaller Psyche" and the Weakness of Human Perception 25I - Second Measure against Decay: Nutrition and Digestion 253 - An Ancient Interpretation 253 - The Genuine Anaxagorean Teaching 255 - And What about Fragment Number Ten ? 256 - Third Measure against Decay: Perception 258 - What Is the Meaning of "Corresponding to the Deficiency..."? 260 - Decay 26I - An Epitomist's Report and Its Anaxagorean Sense 262 - Sleep and Death - Physiologically 263 
Nous Still the Only Person in the Universe 264 - An Enigmatic Fragment 265 - What the Riddle Consists in 266 - Attempts at Elucidation 267 - Conditio Pluralitatis Personarum 268 - Comparison with an Aristotelian Teaching 269 - World-Nous and Separate NousIndividuals 270 - Sleep and Death - Psychologically 272 - The Site of the "Soul" 273 - Conscious and "Unconscious" Occurrences in the Organism 273 - Theory of Perception 274 - No Scepticism in Principle 276 - Physical Pain 277 - Attempt at Reconstruction 278 Physical Delight 280 - No "Pain-and-Delight"-Element 282 - A Gross Misinterpretation 282 - Scanty Reports on Details 283 - Plants, Too, Have Individual Consciousness 285 - An Ungrateful Disciple 286 - An Overdue Vindication of Honor 289 - The Actual Differences in Intelligence 291 - The Aristotle Mystery 292

\section{INFINITY IN SPACE AND TIME}

One Cosmos or Many Cosmoi?

"With Us" and "Elsewhere" 296 - Is the Moon Inhabited? 296 Duration of Cosmogony and the Destiny of the Stars 297 - "The Whole" and "the Wholes" 298 - Witnesses Contesting and Endorsing 299

The Ostensible Beginning in Time

Eudemos' Reproach and Simplikios' Attempt at Refutation 301 Rehabilitation 302 - Eternal Periodicity 303 - Does Pantahomou Imply a Sleep of Nous? 304 - The Three Hellenic Attitudes Regarding Commencement 305 - A Weighty Endorsement 305 - Remarkable Analogies 306

\section{ANAXAGORAS AND POSTERITY}

The Elements - Aristotelian and Otherwise

The Riddle of the Aristotelian Reports 307 - Confusion with Anaximander 308 - A Strange Criticism 309 - A Dubious Evidence against Periodicity $3 \mathbf{I I}$ - Friedrich Nietzsche, Paul Tannery, John Burnet 312 - Eduard Zeller 315

\section{Nous - Aristotelian and Otherwise}

Is Nous "Pure Spirit"? 3I7 - Modern Interpretations 3I7 - New Answer by Counter-Question 320 - Anaxagoras, the Monist, the Dualist, the Pluralist 322 - A Heretic Digression 323-Is Anaxagoras an Inconsistent Teleologist? 324 - Is Nous Really But a Stop-Gap? 325 


\section{VOLUME TWO}

\section{Empedocles of Akragas}

Introduction

The Ostensible Influence of Parmenides 329 - An Iridescent Personality 33I - Chronology 332 - Empedocles' Philosophical Education 333 - Still Another Influence... 338 - The Writings of Empedocles 339

\section{PHILOSOPHY OF NATURE}

\section{The Six Ultimate Constituents}

The Four Elements 342 - The Problem of Motion 346 - Empedocles' World Is Finite 349 - No Void Space in the World 349

\section{The Periodic World Process}

The Sphairos Stage 352 - The Akreta-Zora Stage 357 - The Rise of Organisms 360 - An Ingenious Idea 363 - The Phenomenon of Death 368

Physiological Psychology

Perception of Like by Like 369 - Theory of Vision 372 - Finite Velocity of Light Transmission 377 - Theories of Hearing and Smelling 378 - Is Theophrastus Deserving of Belief? 379 - The Problem of Soul 381

THE KATHARMOI

The Birth-Place of the Souls 387 - The Downfall into Earthly Life 388 - What Empedocles Passes Over in Silence 389 - Not Punishment, but Fate 39J - Empedocles, the Awakener and Prophet. . 39I

The Impact of the Katharmoi 392 - Endurance of the Philosophy 394 - Immortalizing is wer of the Legends 396 


\section{LEUCIPPUS OF MILETUS; DEMOCRITUS OF ABDERA}

Introduction

The Life of Democritus 399 - The Writings of Democritus 40 I - Basic Principles of Democritean Ethics 403-Why Corpus "Democriteum" 405

The Atomistic Doctrine

Symploké and Periplexis 406 - The Giant-Atoms of Democritus 407 Fundamentals of Democritean Atomism 408 - Some Momentous Consequences 410 - Constant and Never Lost Velocities 412 Relation between Velocity and Size 4I4 - The Four Arguments in Favor of Atomism 4I 7 - Atom and Aggregate 4I9 - "Quality-less" and "Unfeeling" 420 - The Fire Atoms 422 - Where Are the Atoms? 424 - Kinds, not Degrees, of Reality 426 - The Disunion in Mind 427 Eteé and Nomo 428 - Gnesie and Skotie 431 - No Metaphysical Construction 433 - Theory of Vision 434 - Two Accessory Questions 438 No "Subject" of Consciousness 438 - "Oh You Pitiable Intellect. . .!" $44 \mathrm{I}$

Democritus and Posterity

The Reactions of Plato and Aristotle 443-Epicurean Bowdlerization 445 - Survival and Revival 446 - "Democritus" versus "Aristotle" 447

\section{The Pythagoreans}

\section{Introduction}

The Peratists 450 - Philolaos 45I - The Five Bodies - "Pythagorean" or "Platonic"? $45^{2}$

\section{The Ten Elements of the World}

Five Bodies - Five Elements 454 - The Five Stuff Elements 456 - The "Power in the Monad" 458 - The Fifth Element 46I - The "Production" of the Atoms 465 - The Ostensible Analogy in India 466 And What about Plato? 468 - The Five Occurrence Elements 473 Why Is the "Soul" a "Harmony"? 478 - The Admiration for the Number Ten 478

The Structure of the World

Uranos, Cosmos, Olympos 480 - The Organisms on the Moon $482-$ The Sun and Its Inhabitants 485 - The Alleged Destruction of the World 487 - Antichthon, the Counter-Earth 489 - Location of the Counter-Earth 490 - From Philolaos to Copernicus 493 - Who Is Turning the Spheres? 494

Metempsychosis and the Alleged Eternal Recurrence of the Same 
The Universal Dichotomy in Nature

The Table of Contrasts 503 - Group Designations 505

The Symbol of Justice

An Ethics of Forms 506 - Comparison with Indian Doctrine 507

Number and the "Essence of Things"

A Source of Misunderstandings 508 - The Nature of Number $510-$ Number - the Secret of Scientific Progress 512

\section{Champions of Culture Politics}

What Exactly Were the Pythagoreans 5I5 - The Example of the Egyptian Priest 517- Pythagoras and the Indians 519

\section{The Glossomorphics}

Parmenides of Elea

Introduction

Formative Influences 525 - Two Cases of "ignotum per ignotius" 526 Parmenides' Philosophical Poem 527

Parmenides' "Truth"

An Ancient "cogito, ergo sum" 528 - The Destruction of a World 530 Being Has Neither Quality Nor Intensity 531 - Space, Too, Is a NotBeing 532 - The Ball Metaphor 533 - A Strange Misinterpretation 535 - No Division of Consciousness 536 - Those Alarming Consequences 538

The Truth about Parmenides " Truth"

The Possibility of Talking without Thinking 538 - The Undoing of the Parmenidean Paralogisms 540 - Closing In for the Undoing 544 Gradation of Reality 545

Parmenides and Posterity

Parmenides' Immediate Disciples 547 - The Zenonic Variety of Glossomorphism 548 - Parmenides' Impact on Subsequent Philosophy 553 - The One Einai and the Many Ontos Onta 553 - True Belief instead of Deceptive Belief 556 - The Einai-Philosophy of Aristotle 557

\section{Indices}

Index of Passages 


\section{ACKNOWLEDGMENTS}

This is to express my deepest thanks to those who have helped me reach the goal.

Ten years ago, in order to enable me to put down in writing these results of a lifetime's endeavors, Dr. Karl E. Ettinger of New York for three years provided, in an indirect way, the means for the leisure so desirable for such a task, by making me apply for a Bollingen Foundation fellowship.

By scrutinizing a great part of the manuscript in its first shape, the late, unforgettable Dr. Erich W. Berger of New York, with his calm, mellowed philological, philosophical, and literary wisdom, time and again in sterling friendship kept me from the pitfalls of impetuosity.

The decisive encouragement came from Professor Richard P. McKeon of the University of Chicago who, after examining for several months the manuscript in its final form, called it, in a momentous letter, "a massive contribution to philosophy and to the history of philosophy."

And last, but not least by any means, I want to thank Melitta, my adorable wife. Without her inexhaustible patience and loving-kindness this work could never have been finished.

Wilmington, Delaware

F. M. C.

October 1964 


\section{FOREWORD}

Again and again and again:

PHILOSOPHIA FIAT, QUAE PHILOLOGIA FUIT!

As a consequence of certain developments in these last hundred years, ancient philosophy has been slipping from the hands of philosophers to become finally an almost exclusive domain of philologists. This has been happening not only because a tremendous amount of genuinely philological work had to be done, and still is needed, in collecting and textually adjusting the pertinent material, but also because a thorough knowledge and command of the ancient languages has become ever more and more of a rarity among philosophers, unfortunately.

From the viewpoint of philosophical culture, this is disastrous. For most philologists are in a state of innocence as far as philosophy is concerned. Of course, they themselves are not aware of it. But the tragicomical fact remains: They have all the answers and do not know the questions. And so, led astray by philosophical misconceptions, they even commit appalling philological blunders every once in a while.

It has been my aim to recapture for philosophy the field of early Greek thought, that fundamentally important period in which, at the very beginning of philosophic speculation, the basic problems emerge, embodied in the various philosopher types. These first two centuries of philosophy in our culture - the time from about 600 to about 400 B.C. appear indeed to be the age of the pure types, of the originals, independent of each other much more than usually realized. For it would be definitely anachronistic to follow the scholars of late antiquity "who 
could not think of an Anaximander but in terms of a 'student' of 'professor' Thales." 1

Socrates, too, would belong to this era, as the last of the originals before the first, grand synthesis, Plato. However, there is no getting over the mysterious fact that no sooner do we try to touch the "real" Socrates than he vanishes into thin air, as it were, or assumes such form and shape that almost nothing but the mere name remains as the common feature of this Athenian character and the hero of a cherished legend. ${ }^{2}$

The Sophists have here not been included, either. Their proper place has recently been made the topic of thorough and mutually independent studies, with new results of importance, by Dupréel and by Mario Untersteiner. ${ }^{3}$

It is still usual to take these early Greek thinkers merely as "forerunners." Yet, now that the scattered literary remains of that period have been collected from all antiquity by philologists, these men, in the light of the sources now accessible, appear to be not only original thinkers in their own right, but even veritable philosophic giants.

These sources, the textual material that has survived the vicissitudes of history and has been handed down to our day, consist of two groupes: the so-called Fragments proper, i.e., literal quotations from the lost writings of the philosophers, and Reports about their lives, works, and teachings, as contained in the writings of other ancient authors. ${ }^{4}$ These reports are of different value and very often can only with the utmost care be used as historical sources. At any rate, here the cardinal rule has to be: Wherever the words of a philosopher, as given in an authentic fragment, contradict the report of a later writer, onc

1 “... qui ne pouvaient concevoir un Anaximandre que sous les traits d'un élève du professeur Thales." (Eugène Dupréel, Les Sophistes: Neuchatel, 1948, p. 402). This anachronistic attitude, however, has again become customary since I887 when Diels adopted it in his writing, Die ältesten Philosophenschulen der Griechen.

2 Cf. Eugène Dupréel, La Légende Socratique et les sources de Platon. Brussels, 1922. Alban D. Winspear and Tom Silverberg, Who Was Socrates? New York, 1939. Olof Gigon, Sokvates: Sein Bild in Dichtung und Geschichte. Bern, r947. Anton-Hermann Chroust, Socrates, Man and Myth. London, 1957, p. XI: “... a hopelessly elusive if not completely legendary figure."

3 Eugène Dupréel, Les Sophistes: Protagoras, Gorgias, Prodicus, Hippias. Neuchatel, 1948. Mario Untersteiner, I Sofisti. Torino, 1949; English translation by Kathleen Freeman. New York, 1954.

4 In the source book, Die Fragmente der Vorsokratiker by Hermann Diels, for each philosopher the Reports are gathered under group A, while the Fragments form group B. 
has to give credence to the philosopher - no matter how famous the name of the reporter. The fragments themselves, however, must be scrutinized "microscopically," as it were. In those olden times, books of philosophy were not written in a hurry ...

When, in the Preface to the first edition (1903) of his ever since indispensable source book, Hermann Diels touched the problem of a meaningful arrangement of the fragments, he declared that he had kept to the principle of giving the fragments merely according to the alphabetical sequence of the names of the authors from whom those literal quotations were taken and that he had discarded any attempt to give them intrinsic coherence. "What is the use," he wrote, "of finding a real or presumed coherence here and there in the tremendous mass of the aphorisms of Heraclitus or Democritus while one still remains helpless in front of their by far overwhelming majority?" 5 Humbly and quite justly, this master philologist restricted himself to "the outward grouping according to the authors." 5 The task of a meaningful arrangement was left.

Afterwards, this task was taken up concerning various individual thinkers of that era, mostly by philologists, sometimes by philologically and linguistically trained philosophers. Not equal to the extraphilological task, the philologists of necessity failed and now and then, honestly enough, even confessed that they had to "capitulate" (to quote one of them). The attempts of the few philosophers, however, were silenced by silence. It became the customary manner of dealing with those so-called Pre-Socratics to pick up from the conglomeration a single fragment here and there and use it as "evidence" for almost any assertion about them, and besides, on the whole, to treat those giants condescendingly as more or less primitive, or "archaic," half-imbeciles who were "not yet able to grasp" this or that (which, however, just a few decades later could be grasped by everybody ...). The pile of fragments was left without arrangement, any attempt at reconstruction was declared as hopeless, and finally, as in a recent book on Greek philosophy, even the very idea of making those precious disjecta membra into meaningful, organic wholes has been dismissed as ridiculous, with the rhetoric question: "Could one reconstruct the

5 "Was hilft es, in dem gewaltigen Haufen der Aphorismen Heraklits oder Demokrits hier und da einen wirklichen oder vermeintlichen Zusammenhang zu finden, wo man doch der weit überwiegenden Mehrzahl gegenüber ratlos bleibt?" (Op. cit., p. VII). "Die äusserliche Ordnung nach den Autoren ..." (ibid.) 
works of Shakespeare out of quotations in Bartlett?" (Needless to say that the analogy is completely misplaced. The same author would hardly doubt that a mathematician, if equipped with the required linguistic tools, could reconstruct a whole from fragments of an ancient mathematician's work.)

Yet, all the same, the task still stands. The task is still, on the basis of the philologists' meritorious philological work, to find out what these philosophers of old, the individual thinkers who constitute "preSocratic philosophy," were actually teaching.

It is not an easy task. No complete works have survived. What has been handed down is much too fragmentary to be pieced together, as in a jig-saw puzzle, into literary wholes. With the extant fragments, a philological reconstruction, a reconstruction of the full texts of those lost writings, is indeed virtually impossible. But something else should not be impossible: reconstruction in a philosophical sense, reconstruction of the doctrines, not of the texts.

Such reconstruction can only be done by way of hypothesis, of course. And the procedure must be: hypothetically to construct philosophic buildings, in the mental styles of the philosophers concerned, in such a way that the authentic material handed down can be fitted in. ${ }^{6}$ This is something quite different from an attempt to make incoherent fragments into a coherent text. To reconstruct the thoughts of those venerable sages and, at the same time, to give them a chance to speak for themselves, finally, with their own words - this has been the foremost and paramount task.

To accomplish this task has been the aim of this work. Nothing more, nothing less. This work, the result of the endeavors of a lifetime, is not a history of the "Hellenic mind" or of the "Ionian tradition" or even of "pre-Socratic philosophy." It deals with concrete, individual philosophers and with the concrete remains of what they thought and taught. Nor is it a string of "papers" or discussions about these doctrines. For it is meant to be a presentation of the doctrines themselves. And it does not touch, either, the question of any pre-philosophical origins.

To unearth the pre-philosophical roots of Greek philosophy is no doubt a fascinating problem. It can be studied best with the help of the

6 Cf. F. M. Cleve, The Philosophy of Anaxagoras. An Attempt at Reconstruction (New York, 1949), p. VIII, and "Understanding the Pre-Socratics: Philological or Philosophical Reconstruction?" in: INTERNATIONAL PHILOSOPHICAL QUARTERLY, vol. III, no. 3 (September, 1963) pp. 445-464. 
writings of a group of British classical philologists ${ }^{7}$ who, under the influence of the hypotheses of French sociologists and anthropologists and, also, of the psychological, or rather metaphysical, hypothesis of "collective archetypes," have applied their scholarship and sagacity to that problem, with results that, as such, are highly interesting, even thrilling. Yet, no help whatsoever has come from these results for the fulfilling of the task of this work, the task of making those jumbled up splinters of philosophy into meaningful doctrines. Besides, however, from the standpoint of philosophy, the fact that certain primordial problems - which naturally are always the same - were attacked, e.g., by Hesiod mythologically and by Anaximander, three-hundred years later, philosophically is a matter of course, anyway. And that the philosophical "modes of thought... were already implicit in the unreasoned intuitions of mythology" 8 cannot detract from the glory of those originals, the Founding Fathers of philosophy.

Just as any period of philosophic thought, those first two centuries of philosophy in our culture can be looked at from different angles. They are a period of Greek literature, of Greek culture, of Greek history in general. But to us, they are a period of the history of philosophy, and not just of Greek philosophy, but of the history of "Western" philosophy, of a history that began with that period and is still going on and on. Our method of treating that period, therefore, will be accordingly different from the methods of the historians of literature, of culture, or of general history: We shall look at it from the viewopoint of the philosophical problems themselves.

In accordance with this approach, the philosophers of this period will not be presented following mere chronology, but in groups corresponding to their various types, and only within the groups in chronological succession.

F. M. C.

7 Mainly F. M. Cornford, E. R. Dodds, W. K. C. Guthrie, a.o.

8 F. M. Cornford, From Religion to Philosophy. London, 1912, p. V. 


\section{SOURCES AND MOTIVES OF PHILOSOPHY}

Philosophy was not always philosophy. The word repeatedly changed its meaning.

"Philosopher," "philosophical man," is an expression to be found for the first time in Heraclitus (floruit ca. 504-50r B.C.). One of his aphorisms runs:

Philosophical men, namely, shall have knowledge of a great many things.

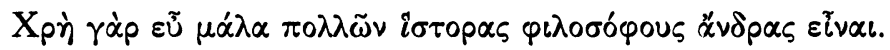

(fr. 35, Diels)

Strangely enough coinciding with modern usage, "philosopher" means here a man searching for ultimate truth.

Apart from this solitary instance, however, "philosophy" was originally equivalent to, and interchangeably used for, "science," "research," "intelligence," "education," "intellectual culture," "mathematics," "geometry," "art of a sensible conduct in life," and "wisdom."

According to Herodotus' narrative (I, 30), King Croesus says to his guest, Solon: "I have heard about your having traveled in many

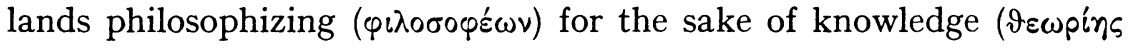

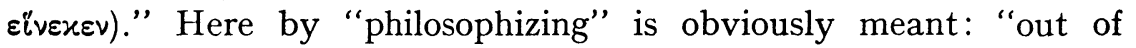
ethnographic, geographic, sociological interest." Or take that famous oration in Thucydides $(2,40)$ where Pericles declares about himself and the people of Athens: "We love luxury without wastefulness and

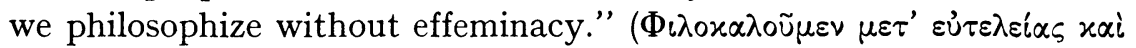

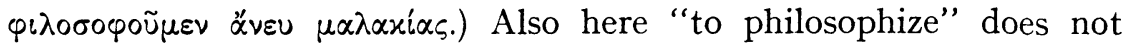
mean philosophize. Pericles merely wants to say: We are striving for intellectual culture, we are refined people, but without getting effemi- 
nated by that. In Plato's dialogue Theaetetus, there is a passage (I43 D)

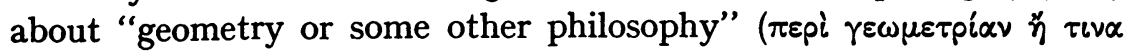
$\alpha \lambda \lambda \eta \nu \nu\left(\lambda 0 \sigma \circ \varphi^{\prime}(\alpha)\right)$. The word is here synonymous with theory in general, geometry being the "philosophy" of space.

From the broad range of meaning a small part was separated as "first philosophy" ( $\pi \rho \omega \dot{\tau} \eta \eta$ phy," or introductory science, was supposed to be "the science of the

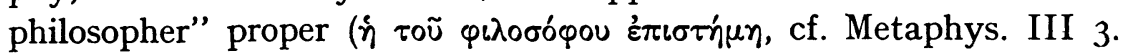
I005a2I). In contrast to the various special sciences, the "so-called

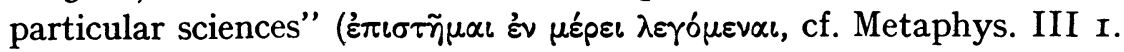
I003a22), this introductory science is to deal with "being as such" ( $\tau$ ò ôv $\hat{n}$ ơv, ibid.), while the subject-matter of zoology, e.g., would be dog-being, horse-being, lion-being, etc.

This division is an historical fact. Whether it makes sense, and whether "being as such," the Aristotelian subject-matter of the philosopher proper, means anything at all, these are questions to be answered in due time.

Later on, when philosophy had become denominational, with Jewish or Christian or Moslem orientations, the term assumed the sense of "worldly science" (Weltweisheit) as contrasted to theology. It came to designate such theoretical knowledge and such practical wisdom as could be obtained through the lumen naturale, the "natural light of reason" alone, as distinguished from cognitions of the supranatural and from those rules of life which were possible through Revelation only. Thus any knowledge belonged to Weltweisheit, and also philosophy insofar as it did not appeal to Revelation.

Actual modern usage distinguishes theoretical philosophy from practical philosophy. ${ }^{1}$

The two fields have very little in common. Theoretical philosophy consists, on the whole, of constructions, conclusions, conceptions, hypotheses, theories. It is a mental beholding and building, the making of a world picture. The philosophy of practice, also called ethics or philosophy of morals, wants to teach how to conduct a sensible life. No doubt, to construct hypotheses is one thing and to live reasonably

1 Both expressions are rather awkward. Properly speaking, there is no such thing as "practical philosophy." What is meant is "philosophy of practice": practice is made a topic of philosophizing. And "theoretical philosophy" would mean "theoretical theory." Yet, the terms are traditional. 
another. The one is an art of living, the other, speculation. And there are those who even maintain that the better artist of life is he who speculates as little as possible. But at any rate, of practical philosophy one speaks only where there is involved some formation of a way of life, some estimation and evaluation, some regulation of the conduct in life by approval and disapproval.

In other words, theoretical philosophy aims at the formation of a world picture that we behold, practical philosophy, at the formation of a life that we live. It may be wise, therefore, not to labor to bring the theoretical and the practical fields under one notion and not to claim for the word "philosophy" the same meaning in each of the two terms. (See, however, p. XXXV)

Theoretic philosophy has got a supplement: epistemology, or the theory of cognition.

In former times, philosophy was considered a cognition beyond experience. Naturally, some day one could not help asking whether such "philosophical" cognition - cognition beyond experience, that is was possible at all. This question was indeed the impulse to the origin of epistemology.

And so, from a certain period on, philosophy has had epistemology as a companion, while in the naive stage philosophers take it unquestioningly for granted that they "cognize."

Therefore, epistemology is not itself a philosophical activity. It is rather an inquiry into, and a criticism of, the feasibility of such philosophical activity, a criticism, however, that presupposes a claim of that activity to be cognition.

Several disciplines have separated from philosophy.

Psychology, e.g., has become a descriptive science. It describes the facts of consciousness, such as facts of sensation, facts of inner perception, facts of dreaming, etc. These facts are of all realities the most real ones anyway (if such a superlative were permitted) and cannot be doubted by any "theory of cognition."

Yet, psychology contains also an hypothetical admixture. Other people's consciousness and one's own so-called "unconscious" whatever this term in fact may mean - cannot be reached as such by introspection. And so, the psychology of the "I" being an exact science, the psychologies of the "Thou" and the "It" are already philosophy, strictly speaking. 
Logic, too, has become independent. The historical fact that persons occupying themselves with logic were usually the same as those interested in philosophy would seem almost a mere accident. They could have been mathematicians as well, and even he who cultivates any science whatsoever is implicitly also a logician.

But it could be that there is a reason why things have come to be as they actually are. In this field, there have been and still are many such problems as can be clarified and solved only when approached from the side of psychology, and particularly psychology of language. Until not so long ago, however, psychology was one of the basic disciplines of philosophy.

Logic, at any rate, is a prerequisite to every science, and it is much too narrow to call it, as has been usual, philosophical propaedeutics, or introduction to philosophy. It is the "propaedeutics" to any science.

The so-called philosophy of art is another field that has got on its own. Today, if to be taken seriously, it is no longer a normative aesthetics, a "prescribing science of the judgments of taste." It has changed partly into history of the arts, partly into physiology and psychology of artistic production and artistic enjoyment. An aesthetics proper, in the old-fashioned manner, seems to have been losing ground.

Theoretic philosophy, then, - to return to what here will be the main topic - is meant as the making of a world picture that would have to reach beyond the frontiers of experience in some way or other: by way of certain cognitions, in the opinion of many; or, according to others, through some sort of revelation; or, as still others believe, by means of artistic imagination.

In the course of the history of philosophy, quite a number of such world pictures have been made. To study them with regard to their contents is, of course, indispensable. But it need not be the only thing to do. In addition, those pictures could also be scrutinized with a view to the motives. One could try to find out, not merely what this or that philosopher says, but also why, also out of which psychological motive and source.

Such quest may not seem to be new. Common opinion has it that at least one of the psychological roots was unearthed by Plato already and Aristotle who are said to have stated that the root of philosophy was amazement.

It will be worthwhile looking into this matter more closely. Painful 
experiences give warning not to place implicit confidence in philosophical quotations. Inexactness is epidemic in this field.

The Plato passage about amazement allegedly being the source of "philosophy" is in his dialogue Theaetetus; the Aristotle passage, in the Metaphysics.

Says Plato:

This feeling of amazement, namely, is very much peculiar of a philosopher: for there is no source of philosophy other than this.

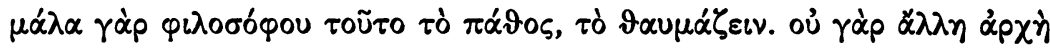

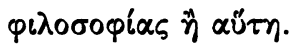

This is in Theaetetus ${ }_{155} \mathrm{D}$. But in a very near neighborhood, $143 \mathrm{D}$,

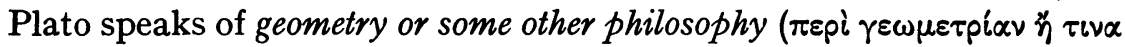
$\alpha \lambda \lambda \eta \nu \varphi(\lambda \circ \sigma \circ \varphi(\alpha \nu)$. Should it not seem obvious that as in $143 \mathrm{D}$ so also in I55D "philosophy" is not what we mean by this term, but is used in that broader sense of "science" and "scientific investigation"? 2

And now the passage in Aristotle (Met. I 2. 982bI2):

For by way of amazement people began to philosophize nowadays as well as in olden times,

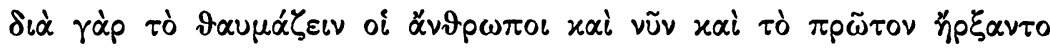

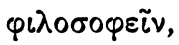

But this is not yet the end of the sentence, and the very continuation after the comma clearly shows that here, too, "philosophize" does not mean philosophize:

first, by getting amazed about the nearest of the startling things; later, by thus making progress little by little and getting puzzled about those bigger things, such as the phases of the moon and the (various problems) concerning the sun and about the stars and the origin of the universe.

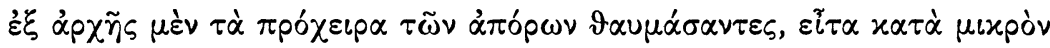

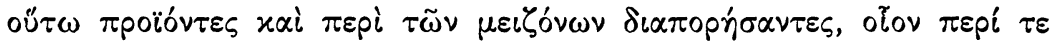

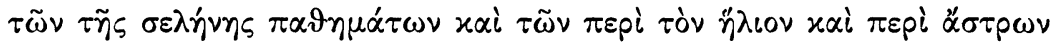

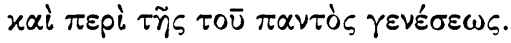

That is to say, it is atronomical, physical, cosmological problems what Aristotle has in mind. Here by "philosophy" he obviously means natural science, hypotheses about nature, at any rate special sciences.

2 See also v. Wilamowitz, Platon, I, 2nd ed. (1920) p. ro8: "Diese Philosophie macht dann Platon zu dem was wir Wissenschaft nennen." 
Thus it seems to have been overlooked that in both passages not philosophy is meant but various special sciences, in Plato such as are in the neighborhood of geometry, and in Aristotle astronomy and the like. Both apparently considered amazement the root of the "sciences in particular," a finding that can readily be adopted as correct.

But even if reference to those passages were justified, one still would have to remember: amicus Plato, amicus Aristoteles, magis amica veritas. For, in fact, never was amazement the root of philosophy.

There are other and entirely different roots of theoretical philosophizing.

An artistic bent for building and moulding is one of the roots.

As long as man is not stunted (by too much one-sided scientific activity, e.g.), as long as he is a whole human being and not yet senile and decrepit, there is in him an artistic bent for building. This he gratifies in various ways and also by complementing the given piece of reality to a whole.

The real as given us is indeed a fragment: it is finite in space, finite in time. We do not know what was before us, we have not seen it. We do not see what will be later, after us. Nor do we see things far away in space, any more than we can see the finest textures. The real as offered us gives an impression of being a fragment of something, and that is a stimulation, a challenge for our building-drive. It provokes it to completing, to building up something whole, in the style of that fragment.

Such completion of the world fragment is performed without any desire for redemption or solace or hope. It is neither in favor of religion nor against it. It is a purely theoretical philosophy, stemming from a purely artistic attitude. If Thales teaches all things consist of water, the consequence is neither hope nor solace. Here only one thing matters: that it be the simplest possible.

But why on earth should it matter whether one assumes one primordial stuff or a hundred? From the practical point of view it does not matter at all. Yet, it certainly is artistic to develop something very complex from something very simple.

Or take those endeavors to arrive at the utmost simplicity of the laws of motion or even, if any possible, one sole such primordial law. This, too, is an artistic ideal, properly. In both instances there is a correspondence with the building style of nature as we see it, and an artistic urge it is to complete a fragment in true style. 
Now, what is meant by "building style of nature"?

There is, e.g., a great number of species of animals and plants, and a small number of elements of which they consist. That means: a few elements and a great many combinations. This clearly is a building style. And it is then gratification of an artistic urge to build even all things out of one element, for instance one primordial matter. (Which is possible in imagination only, of course.)

That the number of properties diminishes ever more, the more one goes down the levels of organization is another example of building style in nature. Birds fly, fish swim - with their whole organisms. That is the topmost level of organization. But a single bone, a single muscle cannot run or spring or swim or fly any more. On the way from tissue to cell the loss continues, and when coming to the molecule there has been still more loss. A single gas molecule, e.g., cannot fall down, but when within an aggregate it can. And the really ultimate particles of material things, finally, have even neither plasticity nor elasticity or hardness nor heat any more. Such an ultimate particle cannot transform "internal movement of its particles" into heat - just because it is only one, single particle. Neither is it plastic or elastic or hard since here there are no particles (in the plural) to shift their positions toward each other. All this gets lost for an ultimate particle. The more one steps down, the smaller becomes the number of properties.

This, too, is a building style of nature. That stimulates imagination into assuming for the ultimate particle only one property and into having all the rest originate from the very aggregation as such. So that even gravitation would not be taken for a primary property, but would have to be constructed as resulting from gravity-less, though moving, particles by way of having them push each other in such a manner as to produce the outward appearance of attraction.

An artistic drive, then, is being gratified by dint of imagination.

Yet, here imagination is not free. It is bound to the building style of nature. Or else no artistic effect will be accomplished. The flashes must come the same way they come to the artist. But then anything that would not conform must be eliminated.

This type of theoretical philosophy, therefore, holds an intermediate position between art and science. Science must not contradict the facts directly. Philosophy must not contradict the facts indirectly, in its consequences.

Accordingly, here inductive inference is not a serviceable method. 
Here one has to guess. When, e.g., constructing the finest textures, one must not merely reduce in size; one also has to simplify. After the discovery by Anthony van Leeuwenhoek (1632-I723) of the spermatozoa, Hartsoeker and Swammerdam believed themselves to see in protoplasm a tiny human being, an homunculus. That was induction. And it was wrong, of course.

Likewise, if we are forced - as in fact we are - to assume a plurality of consciousness-units, this too is no induction. From induction the result would always be restricted to one's own world, one's own consciousness-unit. Imagination it is and a gift for construction, bridled by the facts.

Hence, the outcome is no system of cognitions, but a piece of art.

If one thinks it is cognition, the end is disappointment. If, however, theoretic philosophy is gratification of an artistic bent for building, then a demonstration to the effect that it offers no cognitions cannot inflict any harm to it. For only under the presupposition that it be a system of cognitions has metaphysics been crashed by Kant.

Yet, there is one basic difference between a work of philosophical artistry and any other work of art: We do not believe in a work of art, while philosophical constructions are expected to make us believe in them.

This concomitant belief is indeed indispensable. It arises by way of a psychological and physiological compulsion if a philosophical construction punctiliously follows the style of sense-given reality.

If a philosopher is an artist in spite of himself, he will attach all value to that belief and do all he can to force it by logical operations. In this way, the theoretical philosopher becomes the criticized object of the epistemologist. Is, however, the philosopher aware that he is building in the manner of an artist, then he will calm down in the gratification of his bent and accept that concomitant belief as a welcome additional boon, without laboring to force it by means of logical operations and without talking too much about it. Such belief cannot be forced by any logical operations. But neither can logical operations suppress it.

There are, then, purely theoretic philosophies. For this type of philosophy that, without ulterior motives, merely wants to behold and then, in the style of what had been beheld, build up a whole world picture there is no current name as yet. The Greek word for "spectator"

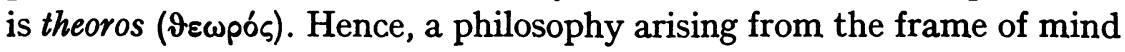


of such a spectator may fittingly be called a theorogon philosophy. ${ }^{3}$

The foremost organ to furnish building material for this type is the eye, the "great sense," as it was called by Anaxagoras, the "king of the senses," according to Leonardo da Vinci.

Many such world pictures have been made, and very different ones. But since they are works of art, and not cognitions, this is not harmful.

The number of those many systems has been diminishing. They have been converging in the long run. In the beginning, there was less science, less factual knowledge, hence less possibility of checking with the facts, and so there was more room for fancy. The greater the number of established facts, the more easily can flashes be checked. As a consequence, from each system something is taken away, and so they come closer and closer to each other. Today they are still widely apart, but obviously much less than, e.g., in 500 B.C.

Thus it could come to pass at some future time that only one such work of philosophical artistry may be feasible and survive. Which then could look like cognition and give the wrong impression as if only one such world picture had been admissible. And yet, it would still not be cognition.

Theorogon philosophy is one type. Its root is definitely not amazement. Here amazement must have already been overcome. Otherwise one would not even have the courage to build and mould.

There is another type. Its source is confusion.

According to the German philosopher, Johann Friedrich Herbart (I776-I84I), all philosophy arises from the confusion of notions and consists in their clarification. This is certainly not true. But it does apply to a very large group.

Speech is earlier than thought. Only when a person forms a word by himself, talking is subsequent to thinking. But whenever a word is accepted ready-made, by a child, e.g., or a pupil, talking precedes thinking. That is why human thinking is to such an extent intermingled with thoughtless talking. A great many people are indeed but pure talking automatons with a minimum of concomitant thought. Thinking can even be downright overpowered by speech. ${ }^{4}$ Then

3 Cf. A. Stöhr, Psychologie, 2nd ed. Vienna, 1922, p. 535.

4 Cf. Ossip Lourié, Le Langage et la verbomanie, Paris, I912, and Le Langage et la graphomanie, Paris, 1922. 
thinking stops completely and talking continues by dint of the brain's being still innervated in a motory way. And for quite a while what has the outward appearance of thinking is mere talking and not thinking at all. On the other hand, when man has to think intensively he stops talking.

Substitution of speech for thought can be, and in fact mostly is, an advantage even, a beneficial arrangement of nature. For if, whenever people are talking, everything had to be clearly and plastically imagined all the time, man would wear himself out prematurely and, besides, what otherwise takes a quarter of an hour would require a whole day. But what usually is an advantage turns into a disadvantage when the mill is running empty.

And so language can become a source of trouble. Messed up grammar, misused metaphors, mistaking metaphors for adequate expressions, taking purely linguistical forms for forms of thought, and the like - all such things make for confusion.

When a man has become confused in this way, he will do all he can to get rid of his confusion - only to get still more confused. Then he will also make other people confused, in order to have somebody to converse with. And as soon as a sufficient number of equally disturbed, "congenial" persons have gathered around such a man, they form a new philosophical school.

It will be a mere word philosophy. By thinking one cannot get into confusion. Nonsense comes into the world by way of speech. A circular quadrangle can only be talked.

A word philosopher can, of course, not by any means be made to realize that he is a talking machine. One just has to leave him alone. But it is easy to learn his language. All one has to do is listen attentively and find out those words, those "technical terms," at which he obviously does no longer think at all, and then use those terms in the same associations and concatenations as he does ...

To this type, the glossogon 5 type, belongs an enormous part of Western philosophy. (Indian philosophy seems to suffer from the same disease to a considerably lesser extent.) The history of theoretic philosophy in Western civilization, as far as not the theorogon type is concerned, is in the main the history of a battle being fought between talking and thinking.

The domain of glossogon philosophy is gigantic, its menace to 5 "Glossogon" means "arisen from language" (cf. Stöhr, l.c.). 
culture, horrifying. Cultural progress would require a steady diminishing of this type of philosophy until, due to man's increased capacity of thinking, it might by self-dissolution eventually disappear.

Of theorogon philosophy the opposite holds true. Here to stop philosophizing would mean to stop being an artist and to become but a shriveled scholar.

In the course of history, there was first an increase of the glossogon type. Today its culmination may have already been passed, but there is still present a vast lot of it. Whether its complete elimination will ever come true is quite a question. At any rate, it may take some thousands of years until then.

Glossogon philosophy is not aware of its origin. If it were, it would not exist.

It produces a self-delusion of some resemblance to mathematics and geometry. Just as these need neither experiments nor even any ordinary accidental experience for arriving at their cognitions, so philosophy, too, it is contended, requires no empirical contents as a material to be complemented by construction, but allegedly can deduce cognitions from mere notions.

Yet, in mathematics and geometry there is an equivalent for the passively received observation or actively arranged experiment of the natural scientist: intuition that can be constructed anew any time. And besides, there are in mathematics and geometry all kinds of substitutions and other invented operations. The mathematician does not say, as does the mathematizing philosopher: 4 is 4 , or 4 is not not-4. The mathematician says, 2 times 2 is 4 , after having invented the operation of multiplying, or the arrangement I, 2, I, 2. The mathematizing philosopher has no invented operations for his deductions to refer to. The equations, "A = A" and "A = not not- $\mathrm{A}$," merely formulate the rejection of nonsense, but nothing new is obtained in this way.

Glossogon philosophy does not consider itself sterile and barren ...

There is still a third root of philosophy: the fact of suffering.

Every human being suffers from life more or less. This is the most characteristic feature, if not the essence, of human existence. These sufferings are of a vastly variegated nature and spring from different fountains.

Subhuman nature is one of the sources. The animal world, the 
vegetable world, and lifeless matter are not only causes of joy. They also are, and even more than today were in earlier periods of mankind, a source of fright and misery, danger and trouble.

Man suffers also from his own nature. His heart is full of enemies playing him nasty tricks, enemies such as foolishness, laziness, ignorance, intemperance, passionateness, and what other names they may have.

An overflowing well of suffering, furthermore, is the fellow-man who so often is the anti-man, the foe in the battle of life. And who can deny that that sentence in Plautus, homo homini lupus, is wrong only in so far as a wolf can never be so cruel, so bestial, or rather so human, so humanly vicious and mean, as human beings can be to each other.

Man defends himself against all these sorts of suffering by deeds and omissions. And the so-called progress of mankind is greatly an increasing development of devices for choking those fountain-heads of suffering. Worship of ghosts is the method by which primitive man is seeking protection from the terror of nature. The next step is sorcery: humble and stooped originally, man now stretches his hand out for a share in the power of the ghosts over the powers of nature. And at the end of that same road, there is the modern art of control over nature by means of mathematics, science, and technology. The enemies in man's own heart are being weakened by ever more improved methods of education, by training in the art of self-control and of finding, and keeping to, the middle of the road between the extremes, equally dangerous, of ascetic resignation and excessive indulgence. And also the evils stemming from men's living together are being fought against with all kinds of endeavor for an ever more increasing betterment of human society.

Yet, that list of the sources of suffering is not complete. Supposing man had already won unlimited control over nature - subhuman nature, that is - and it were perfectly pliable to all his wishes and needs; also the inner foe were conquered, and every man's breast were filled with harmony and peace; and relations between men were resembling those ideal conditions of the Golden Age that, according to the poet, vindice nullo sponte sua sine lege fidem rectumque colebat - even then there would still remain quite enough of suffering that could not be removed or even only mitigated by any deeds or omissions. There is no invention to eliminate the fact of death, not to mention so many other instances. Already Old Homer distinguishes between suffering

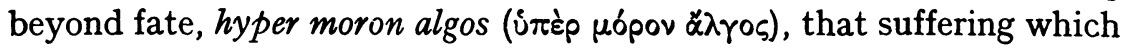




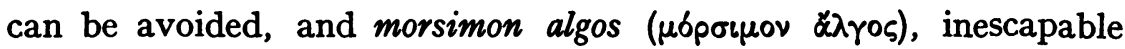
suffering, unavoidably connected with human nature, imposed by some superhuman might, by an inevitabile fatum, no matter whether that fatum be thought of as blind or otherwise.

Man defends himself against this morsimon algos, too, but not by deeds or omissions, these being of no avail against fate. However, although he cannot diminish that kind of suffering, he wants at least to learn how to bear it better. And that is where philosophy comes in:

At first sight, such suffering appears to be altogether senseless, useless, a matter of sheer accident. Nothing, however, is so torturing and embittering as that. And it is an incontestable fact that no sooner does man believe that he has found out some meaning and aim of his suffering than he feels it less grievous and easier to endure. Hence, unawares procreated by the will to suffer less, there grows in him a desire to guess a meaning behind his suffering, and the result is a philosophy with a sense-giving faith, a world interpretation, by which the fact of suffering, though unchanged in itself, is shifted into a different light, appears meaningful and, just by that, does no longer hurt so much.

Here belong all those systems of philosophy which stem neither from an artistic delight in beholding and building nor from confusion by linguistical troubles not recognized as such. But likewise all religions come under this notion of a system of faith to mitigate suffering from destiny by giving it some meaning. Psychologically, there is no difference. The root as well as the end is the same.

It is the will to suffer less, the will to survive, that here, unconsciously, is forming certain imaginations and symbols beyond experience and also the concomitant faith in those imaginations and symbols.

The Greek word for "suffering" is pathos ( $\pi \dot{\alpha} \vartheta \circ \varsigma)$, the word for

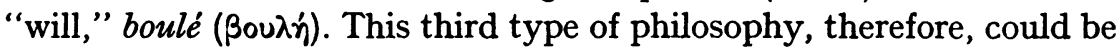
called pathogon or, which amounts to the same, boulogon (cf. Stöhr, l.c.).

With the pathogon type, the contents of faith is pronounced without proofs. Arguments are neither offered nor asked for nor missed - originally. Only afterwards grows a wish for argumentation. Which is usually a sign indicating that that will has been losing strength, and that the boulogon philosophy is going to be shifted upon a new fundament and given the outward appearance of a theorogon or a glossogon philosophy, as the case may be, in the hope thus to prevent the boulogon edifice from crumbling: faith labors to become cognition. 
Yet, pathogon philosophy never seeks cognition for the sake of cognition, but for the sake of solace and hope or, at least, tranquillity of mind. Accordingly, any pathogon philosophy develops from the very outset so as to yield somehow such emotional fruit.

These, then, are the three types of theoretic philosophy, with regard to the psychological root.

Theorogon as well as glossogon and pathogon wefts are in the texture of virtually every philosophical system. Yet, almost in any system one of the three wefts is conspicuously predominant, in accordance with the root predominant in any given case, be it the phantasy of the artist, the sentiment of the sufferer, or the tongue of the confused. On the prevalent root depends the overall character and emotional hue of a philosophy.

But the builder of a decidedly theorogon system may nevertheless become a word philosopher once in a while, whereas another man's philosophy is glossogon throughout, a few plastic images here and there notwithstanding, mostly borrowed from somewhere else.

Of pathogon philosophers, however, there are two sorts. The one operates with visual and plastic constructions as in a theorogon system. Yet, all is in the service of the pathogon goal and appealing to emotion. The other operates with mere words, though, like the spinner of a glossogon yarn. But the difference is unmistakable, all the same. It is always easily felt whether a man is a pure word philosopher or whether his dry, "discoursive" verbiage is fraught with sentiment and feeling and, in fact, is merely the garment of a pathogon philosophy.

In the beginning of these introductory remarks, it has been said that theoretical philosophy and practical philosophy, or ethics, are two completely different fields. This statement has now to be somewhat qualified. For in a certain area the two are overlapping.

Practical philosophy and the theorogon sort of theoretical philosophy are indeed two separate things. Whether, e.g., a hypothesis assumes that atoms have the shape of a ball or of a cube, that they are impenetrable or penetrable, or even that atoms do not exist at all, but instead perhaps a continuous filling of space, this has no impact on the conduct of our lives.

Neither has glossogon philosophy. This species of babbling in a 
sophisticated manner is disastrous for culture, it is true. But it is a private matter, after all, for a person to take pleasure in such verbiage. And if a grown-up man is spending his life on such-like things, he is probably good for nothing better anyway.

At any rate, correct judgment of theorogon as well as glossogon philosophies will be the more facilitated, the more they are separated from ethical problems.

The gist and goal of pathogon philosophy, however: solace and hope, easier endurance of one's fate - these are things that do belong to our behavior in life. For, above all and in the first place, the art of living is the art of keeping us alive.

Every human being suffers from life more or less. But in the course of time, man accumulates experiences about how to diminish those sufferings: the bare fact of living is elevated to an art of living. Not that the art of living would entirely consist of ways and means to diminish suffering. There is also the sum total of endeavors and practices to increase enjoyment. But here we are concerned with that other part only, the negative aim of which is prevention and alleviation of suffering.

Such art of living, or biotics, practiced first instinctively and changing later into conscious maxims, is not yet ethics (just as that other part of biotics, with the positive aim of enjoyment, is not yet culture). It is merely just an art of living that the individual uses for himself, without giving away, let alone recommending, his secret wisdom to another person, except perhaps a beloved son or so. It is not yet ethics nor does it always have an ethical contents, even, but everybody just strives, in the first place, for such an art of living as is adequate to his individual constitution and his sphere of power. Only if and when such art of living is made the norm and standard for the whole community, biotics changes into ethics.

That part of biotics which is a defence against suffering, and accordingly also ethics later on, has four divisions, in correspondence with those four sources of suffering: subhuman nature, man's own nature, his living together with fellow-men, and superhuman powers (cf. p. XXXIIff.).

It is in the fight against suffering from superhuman powers that theoretical philosophy and practical philosophy are overlapping.

From the desire to bear an inevitable fate in the best and worthiest manner, from the desire for solace and hope, unawares arises either a religion or a pathogon, boulogon philosophy, the one being a mass 
phenomenon around the strong personality of the founder, ${ }^{6}$ the other taking form independently in the individual philosopher.

Not deeds and omissions, but that unwittingly grown faith is here the weapon. The fate of the individual is not changed as such. Yet, it appears in a different light and, just by that, is more easily endured.

Pathogon, boulogon faith is sometimes concerned with another world "beyond," the external world, the metaphysical, that can give this world, the phenomenal, another meaning or even some meaning at all. And sometimes such faith, without metaphysics in the narrower sense, refers to a far distant future in this world, to future conditions of this phenomenal reality. In the latter case, the boulogon trait consists in giving the pictures of the future the nicest possible qualities. What is lacking in exact proof is supplemented by the will.

These two sorts of pathogon faith are frequently in a relationship of mutual competition.

Insofar as such a faith - as basis of an art of suffering in dignity and beauty under an inevitable fate - refers to a so-called metaphysical contents, this part of practical philosophy virtually coincides with the pathogon sort of theoretical philosophy.

That is also why, when treating history of philosophy, one cannot separate the two fields completely. For otherwise one would either have to eliminate from theoretical philosophy all the pathogon components and, by that, deprive it of one of its most interesting parts, or one would have to restrict practical philosophy to nature control, self-control, and social problems.

Such restriction of ethics is possible, though. There are indeed certain modern schools of thought that on principle would reject any ethics of faith, as if ethics were without remainder resolvable into those three parts or even into social ethics alone.

But such elimination would at the same time also block the road to any deeper understanding of the facts involved.

Suffering from fate is a fact, and man's shifting of such suffering into a meaningful light is a fact. That such shifting is done in more than one way, and that each of these ways means an alleviation, is another fact as well as that each of them has the tendency of becoming normative. As a consequence, there then arise conflicts of Weltanschauung,

6 Religion belongs to both ethics and culture. As a faith yielding hope and solace, it is a pathogon alleviation of suffering and, therefore, ethics. Since it is connected also with positive constructions, it is culture. 
clashes of the faiths, and religious wars. These conflicts, these clashes, these wars, however, are the most embittered and hottest of all. For what is involved here, affects man most intimately. All these are indubitable facts.

To ignore these facts, by eliminating faith from the field of ethics, would mean to be blind to human passions, to be of a dull, insensible nature oneself, and to presuppose that in this respect all men are equally insensible and dull ... 


\author{
THE GIANTS \\ $\mathrm{OF}$ \\ PRE-SOPHISTIC \\ GREEK PHILOSOPHY
}

AN ATTEMPT TO RECONSTRUCT THEIR THOUGHTS 
The works of the more ancient philosophers were in being till the inundation of the barbarians upon the Roman empire. Only then from the general shipwreck of human learning the philosophies of Aristotle and Plato were preserved in the waves of the ages, like planks of a lighter and less solid nature.

Francis Bacon, Novum Organum Scientiarum, I 77.

It is really most disastrous that of those earlier philosophic masters so little has remained, and that we have been deprived of anything complete. Because of that loss, we unintentionally measure them in wrong proportions and allow ourselves to be influenced against them by the merely accidental fact that Plato and Aristotle have never been short of praisers and copyists. ... Probably the grandest part of Greek thought, and of its expression in words, has got lost.

Friedrich Nietzsche, Die Philosophie im tragischen Zeitalter der Griechen. 